\title{
Prevalence of pancreaticobiliary reflux in symptomatic cholelithiasis and its significance
}

\author{
T P Bohara, ${ }^{1}$ A Parajuli , ${ }^{2}$ G R Bajracharya , ${ }^{3}$ M R Joshi ${ }^{4}$ \\ ${ }^{1}$ Lecturer, ${ }^{2}$ Resident, ${ }^{3}$ Medical Officer, ${ }^{4}$ Associate Professor, Department of Surgery, Kathmandu \\ Medical College Teaching Hospital, Sinamangal, Kathmandu
}

\section{Abstract}

\section{Aims}

Pancreaticobiliary reflux (PBR) is reflux of pancreatic enzymes into the biliary tree which occurs as a result of an anamoly of pancreaticobiliary junction (PBJ) or functionally impaired sphincter. PBR is associated with changes in biliary epithelium and is known to cause benign and malignant biliary pathology. Various authors have reported prevalence of PBR in patients with normal PBJ ranging from $20 \%$ to $83.5 \%$. With aim to detect the prevalence of PBR in patients with symptomatic cholelithiasis in Nepalese population we conducted this study.

\section{Materials and methods}

Thirty patients undergoing elective laparoscopic cholecystectomy (LC) for symptomatic cholelithiasis were included in the study. History, physical findings and relevant investigations including liver function test, serum amylase and abdominal ultrasound were recorded. Bile sample for amylase was taken from gall bladder during LC percuatneously before manipulation of calot's triangle and common bile duct. Bile amylase level above serum amylase level was considered positive for PBR.

\section{Results}

Mean age of the patient was 37.27 ( \pm 14.41$)$ years. Out of 30, $6(20 \%)$ patients were male and $24(80$ $\%)$ were female. Mean BMI was 21.58 ( \pm 3.2 ). PBR reflux was present in $66.7 \%$ of patients out of which 2 were male and 18 were female that was not statistically significant $(p=1.41)$ when compared with patients without PBR.

\section{Conclusion}

PBR occurs in patient with cholelithiasis and has role in pathogenesis of gallstones disease and gall bladder carcinoma. Long term surveillance would be required to ascertain the significance of detection of PBR after LC.

\section{Key words: Cholelithiasis, cholecystectomy, pancreaticobiliary reflux.}




\section{Introduction}

Pancreaticobiliary reflux (PBR) is reflux of pancreatic enzymes into the biliary tree. PBR may occur either as a result of an anatomically abnormal pancreaticobiliary junction or because of a functionally impaired sphincter. ${ }^{1}$ It usually occurs in patients with pancreaticobiliary maljunction and recently PBR is known to occur in patients with normal pancreaticobiliary junction. ${ }^{2,3}$ PBR is associated changes in epithelium of biliary tract resulting in proliferation, hyperplasia and carcinoma. ${ }^{4-6}$

Various authors have reported different prevalence of PBR in patients with normal pancreaticobiliary junction ranging from $20 \%$ to $83.5 \% .^{7-9}$ Normal values of pancreatic enzymes in bile has not yet been determined and validated and so is the method of sampling bile for the analysis. ${ }^{3}$ Beltran $\mathrm{MA}^{10}$ suggested that the most accurate method to measure PBR is directly sampling of bile from gall bladder during cholecystectomy, before any manipulation in triangle of Calot's area or over common bile duct has been performed. Normal values of pancreatic enzymes in plasma have been used as reference to differentiate patients with PBR from without. ${ }^{10-15}$

With aim to detect the true prevalence of PBR in patients with symptomatic cholelithiasis in Nepalese population we conducted a prospective study.

\section{Materials and methods}

Prospective observational study was designed. Patients undergoing laparoscopic cholecystectomy for symptomatic cholelithiasis in Department of General Surgery, Kathmandu Medical College Teaching Hospital from July 2012 to December 2012 were included in the study. Patients who have undergone preoperative endoscopic cholangiography or sphincterotomy, who have suspected biliary tract abnormality and malignancy and who didn't give consent for the study were excluded from the study. Written informed consent was taken from the patient. Eligible patient were assessed preoperatively. History, physical findings and relevant investigations including liver function test (LFT) and abdominal ultrasound (AUS) were recorded in a performa. The day before surgery a blood sample was drawn to measure serum amylase. The procedure during operation was same for all patients. Bile sample were taken from gall bladder percutaneously after insertion of umbilical and epigastric port with 21 Fr G needle before any manipulation of area of Calot's triangle and common bile duct was done and was sent to determine amylase level (Figure 1). Operative findings were also recorded.

\section{Figure 1: Sampling of bile from gall bladder}

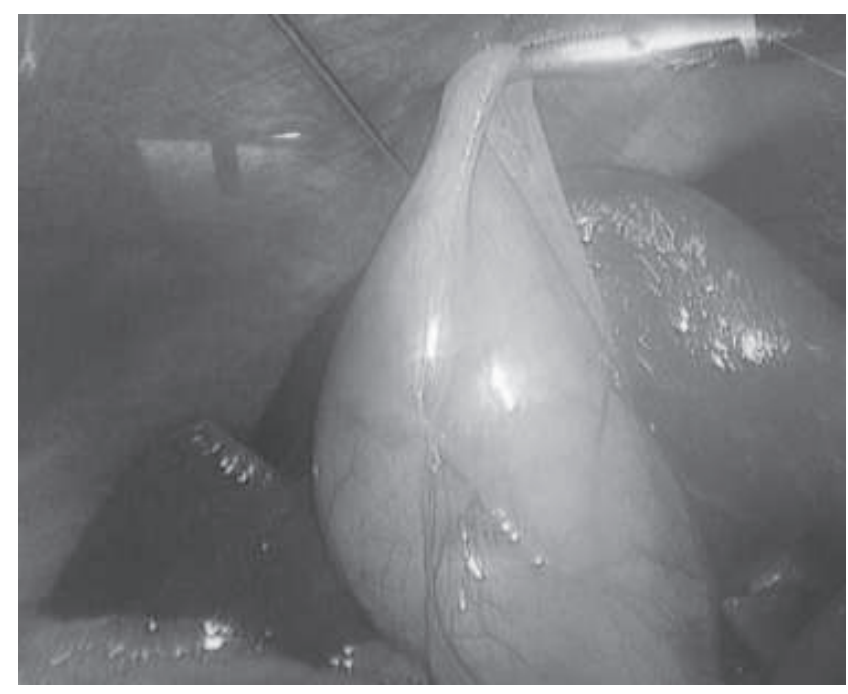

As normal value of bile amylase is not known, serum amylase level was taken as reference. Value of bile amylase above serum amylase was considered as evidence of PBR. Patients were divided into two groups 
TP Bohara et al., Prevalence of pancreaticobiliary.

based on presence and absence of PBR and various variables were compared.

\section{Statistical methods}

Categorical variables were expressed as proportions and continuous variables as mean, standard deviation, and range. Chi square and Man Whitney test was used to compare between groups. $\mathrm{P}$ value $<0.05$ was considered significant. SPPS 15.0 was used for analysis.

\section{Results}

Thirty eight patients were included in the study. Bile amylase level could not be estimated in 8 patients, because of inability to obtain bile during laparoscopic cholecystectomy in 3 patients and in 5 patients bile could not be analyzed because bile was thick or filled with sludge which was inappropriate for analysis. 30 patients were included for analysis of data. All patients underwent laparoscopic cholecystectomy and there was no conversion to open technique.

Mean age of the patient was $37.27( \pm 14.41)$ years. Out of 30, $6(20 \%)$ patients were male and 24 (80 $\%)$ were female. Mean BMI was $21.58( \pm 3.2)$ as shown in Table 1.

Table 1: Demographic and clinical characteristics

\begin{tabular}{lc} 
Variable & Total \\
\hline Age (in Years) & $37.27 \pm 14.41$ \\
\hline Sex & $6(20 \%)$ \\
Male & $24(80 \%)$ \\
Female & $21.58 \pm 3.2$ \\
BMI $\left(\mathrm{kg} / \mathrm{m}^{2}\right)$ &
\end{tabular}

Means of Liver function test, serum and bile amylase are shown in table 2.

Table 2: Mean of LFT, serum and bile amylase

\begin{tabular}{lcccc}
\hline \multicolumn{1}{c}{ Test } & Minimum & Maximum & Mean & Std. Deviation \\
\hline Total Bilirubin(mg/dl) & 0.6 & 1.4 & 0.82 & 0.2 \\
DirectBilirubin(mg/dl) & 0.2 & 0.9 & .31 & .19 \\
AST (U/L) & 21 & 228 & 52.07 & 57.90 \\
ALT (U/L) & 16 & 267 & 61.07 & 81.36 \\
ALP(U/L) & 95 & 625 & 267.26 & 134.04 \\
Serum Amylase (U/L) & 90 & 329 & 190.66 & 58.09 \\
Bile Amylase & 15 & 30426 & 2698.67 & 7591.85 \\
\hline
\end{tabular}


PBR reflux was present in $66.7 \%$ of patients out of which 2 were male and 18 were female that was not statistically significant $(\mathrm{p}=0.141)$ when compared with patients without PBR as shown in Figure 2

Figure 2: Distribution of Sex among patients with and without PBR

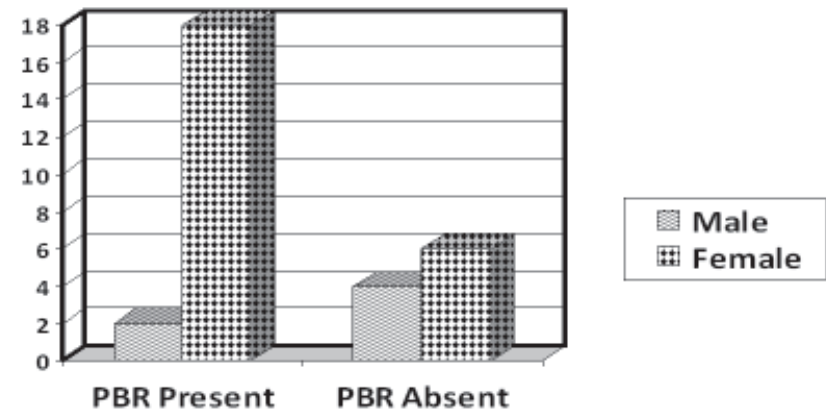

Patients were divided into two groups on the basis of presence and absence of PBR. Various biochemical parameters were compared to detect any difference between two groups. LFT and serum amylase were comparable between the groups without any significant difference as shown in Table 3

Table 3: Comparison of biochemical parameters between patients with and without PBR

\begin{tabular}{lccc}
\hline Variable & PBR Present & PBRAbsent & Pvalue \\
\hline Total Bilirubin (mg/dl) & 0.85 & 0.78 & 0.379 \\
Direct Bilirubin & 0.33 & 0.28 & 0.527 \\
AST (U/L) & 66.2 & 23.8 & 0.062 \\
ALT (U/L) & 76.9 & 29.4 & 0.134 \\
ALP (U/L) & 265.8 & 270.2 & 0.934 \\
Serum Amylase (U/L) & 187.1 & 197.8 & 0.643 \\
\hline
\end{tabular}

\section{Discussion}

Recently it has been recognized that PBR occurs with normal pancreaticobiliary junction. ${ }^{2,3}$ This can be demonstrated by presence of pancreatic enzymes in bile sampled from common bile duct (CBD) during ERCP, bile sampled from gall bladder during operation or by MRCP evidence of biliary tract dilation after secretin injection. ${ }^{13}$ As suggested by Beltran MA ${ }^{10}$ sampling from CBD by ERCP seems to be inappropriate because sphincter of oddi is disrupted during the procedure potentially causing PBR and MRCP is not justified in patients with symptomatic gallstones who are planned to undergo cholecystectomy. We agree with Beltran $\mathrm{M} \mathrm{A}^{10}$ that most accurate method of determining PBR is to take sample from gallbladder during cholecystectomy before any manipulation in calot's area and CBD.

Horaguchi et $\mathrm{al}^{7}$ and Sakamoto et $\mathrm{al}^{8}$ have reported $26 \%$ and $20 \%$ PBR in patients with normal pancreaticobiliary junction. They also found positive correlation with mucosal metaplasia of gallbladder. However our study revealed $66.7 \%$ PBR which is comparable to $87 \%$ reported by Anderson et al ${ }^{16}$ and 83.5\% PBR in patient with normal pancreaticobiliary junction as reported by Beltran et al. ${ }^{9}$

In a prospective study of comparision of gall bladder amylase levels during cholecystectomy in patients with and without gallstones Beltran et $\mathrm{al}^{9}$ reported statistically significant high bile amylase level in patients with gall stones and without $(83.5 \%$ vs $6 \%, \mathrm{p}<0.0001)$. They 
T P Bohara et al., Prevalence of pancreaticobiliary.

suggested that PBR may cause chronic injury to gall bladder and biliary tract mucosa and as bile is further concentrated in gall bladder, the protein concentration is increased which shortens the nucleation time ultimately leading to sludge and stone formation. ${ }^{9,17}$ Anderson et $\mathrm{al}^{16}$ also suggested that reflux of pancreatic enzymes may initiate chronic inflammatory changes in gall bladder and could play a role in gall stone formation and in the pathogenesis of some cases of acute cholecystitis. Varcko et $\mathrm{al}^{11}$ have stressed on the role of PBR in acute cholecystitis and postulated that endoscopic papillotomy releasing the common channel outlet obstruction could initially improve the course of acute cholecystitis in elderly patient, reducing risk of biliary sepsis and delaying surgery until there condition improves.

PBR has role in pathogenesis of various benign gall bladder diseases and is a risk factor for gall bladder carcinoma. In a review article Williams $\mathrm{N} E$ et al ${ }^{1}$ recommended prophylactic cholecystectomy if the diagnosis of PBR is made during any intervention other than cholecystectomy. However significance of detection of PBR after cholecystectomy still eludes medical literature. There are no recommendations for further follow up of these patients with PBR after cholecystectomy. Further research with long term surveillance would be required to ascertain the clinical significance of detection of PBR after cholecystectomy. Limitation of the study: Evaluation of pancreaticobiliary junction by ERCP, MRCP or intraopereative cholangiogram was not done because these investigations are not done routinely for symptomatic cholelithiasis. However patients with dilated biliary system and suspected biliary malignancy were excluded.

\section{Conclusion}

PBR occurs in patient with cholelithiasis and has role in pathogenesis of gallstones disease and gall bladder carcinoma. Long term surveillance would be required to ascertain the significance of detection of PBR after cholecystectomy.

\section{References}

1. Williams NE, Gundara JS, Hugh TJ et al. Many faces of pancreaticobiliary reflux. ANZ J Surg. 2012;82(6):403-7.

2. Sai JK, Suyama M, Kubokawa Y, et al. Occult pancreatobiliary reflux in patients with a normal pancreaticobiliary junction. Gastrointest Endosc. 2003;57(3):364-8.

3. Sai JK, Ariyama J, Suyama M, et al. Occult regurgitation of the pancreatic juice into the biliary tract: diagnosis with secretin injection magnetic resonance cholangiopancreatography. Gastrointest Endosc 2002;56(6):929-32.

4. McKee MD. Pancreaticobiliary reflux and gallbladder cancer. J Surg Oncol 2007; 96(6): 455-6.

5. Kimura K, Ohto M, Saisho H, et al. Association of gallbladder carcinoma and anomalous pancreaticobiliary ductal union. Gastroenterology 1985; 89(6):1258-65.

6. Hanada K, Itoh M, Fujii K, et al. Pathology and cellular kinetics of gallbladder with an anomalous 
junction of the pancreaticobiliary duct. Am J Gastroenterol 1996; 91(5):1007-11.

7. Horaguchi J, Fujita N, Noda Y, et al. Amylase levels in bile in patients with a morphologically normal pancreaticobiliary ductal arrangement. $J$. Gastroenterol. 2008; 43(4): 305-11.

8. Sakamoto $\mathrm{H}$, Mutoh $\mathrm{H}$, Ido $\mathrm{K}$ et al. Intestinal metaplasia in gallbladdercorrelates with high amylase levels in bile in patients with a morphologically normal pancreaticobiliary duct. Hum. Pathol. 2009; 40(12):1762-67.

9. Beltran M, Contreras M, Cruces K. Pancreaticobiliary reûux in patients with and without cholelithiasis: is it a normal phenomenon? World J Surg. 2010; 34(12): 2915-21.

10. Beltrán MA. Pancreaticobiliary reflux in patients with a normal pancreaticobiliary junction: Pathologic implications. World J Gastroenterol. 2011; 17(8): 953-62.

11. Vracko J, Wiechel KL. Increased gallbladder trypsin in acute cholecystitis indicates functional disorder in the sphincter of Oddi and could make EPT a logical procedure. Surg Laparosc Endosc Percutan Tech 2003; 13(15):308-13.
12. Itokawa $\mathrm{F}$, Itoi $\mathrm{T}$, Nakamura $\mathrm{K}$, et al. Assessment of occult pancreatobiliary reflux in patients with pancreaticobiliary disease by ERCP. $J$ Gastroenterol 2004; 39(10): 988-94.

13. Kamisawa T, Anjiki H, Egawa N. Diagnosis and clinical implications of pancreatobiliary reflux. World J Gastroenterol 2008; 14(43):6622-6.

14. Beltrán MA, Vracko J, Cumsille MA, et al. pancreaticobiliary reflux in gallbladder cancer and benign gallbladder diseases. $J$ Surg Oncol.2007;96(1): 26-31.

15. Vracko J, Wiechel KL. Trypsin level in gallbladder bile and ductitis and width of the cystic duct. Hepatogastroenterology 2000; 47(31):115-20.

16. Anderson MC, Hauman RL, Suriyapa $C$ et al. Pancreatic enzyme levels in bile of patients with extrahepatic biliary tract disease. Am J Surg. 1979; 137(3): 301-6.

17. Ko C, Schulte S, Lee S. Biliary sludge is formed by modiûcation of hepatic bile by the gallbladder mucosa. Clin Gastroenterol Hepatol.2005; 3(7): $672-8$. 